\title{
Citicoline induces angiogenesis improving survival of vascular/human brain microvessel endothelial cells through pathways involving ERK1/2 and insulin receptor substrate-1
}

\author{
Vascular Cell 4:20 I DOI: 10.1186/2045-824X-4-20 I C Li et al.; licensee Publiverse Online S.R.L. 2012 \\ Received: 10 Sep 2012 । Accepted: 27 Sep 2012 | Published: 10 Sep 2012 \\ Krupinski Jerzy $^{@}$, Abudawood Manal, Matou-Nasri Sabine, Al-Baradie Raid, Petcu Eugen Bogdan, \\ Justicia Carlos, Planas Anna, Liu Donghui, Rovira Norma, Grau-Slevin Marta, Secades Julio, Slevin Mark \\ ${ }^{+}$Contributed equally ${ }^{@}$ Corresponding author
}

\begin{abstract}
Background

Citicoline is one of the neuroprotective agents that have been used as a therapy in stroke patients. There is limited published data describing the mechanisms through which it acts.
\end{abstract}

\section{Methods}

We used in vitro angiogenesis assays: migration, proliferation, differentiation into tube-like structures in Matrigel ${ }^{\mathrm{TM}}$ and spheroid development assays in human brain microvessel endothelial cells (hCMEC/D3). Western blotting was performed on protein extraction from hCMEC/D3 stimulated with citicoline. An analysis of citicoline signalling pathways was previously studied using a Kinexus phospho-protein screening array. A staurosporin/calcium ionophoreinduced apoptosis assay was performed by seeding hCMEC/D3 on to glass coverslips in serum poor medium. In a pilot in vivo study, transient MCAO in rats was carried out with and without citicoline treatment (1000 mg/Kg) applied at the time of occlusion and subsequently every 3 days until euthanasia (21 days). Vascularity of the stroke-affected regions was examined by immunohistochemistry.

\section{Results}

Citicoline presented no mitogenic and chemotactic effects on hCMEC/D3; however, it significantly increased wound recovery, the formation of tube-like structures in Matrigel $^{\mathrm{TM}}$ and enhanced spheroid development and sprouting. Citicoline induced the expression of phospho-extracellular-signal regulated kinase (ERK)-1/2. Kinexus assays showed an over-expression of insulin receptor substrate-1 (IRS-1). Knock-down of IRS-1 with targeted siRNA in our hCMEC/D3 inhibited the pro-angiogenic effects of citicoline. The percentage of surviving cells was higher in the presence of citicoline. Citicoline treatment significantly increased the numbers of new, active CD105-positive microvessels following MCAO.

\section{Conclusions}

The findings demonstrate both a pro-angiogenic and protective effect of citicoline on hCMEC/D3 in vitro and following middle cerebral artery occlusion (MCAO) in vivo .

\section{Keywords}

Citicoline - Angiogenesis - Apoptosis - Stroke - Ischaemia - IRS-1

\section{Background}

Citicoline, is an essential component of cell membrane phospholipids, and is one of the neuroprotective agents that have been used as a therapy in stroke patients. It has been extensively tested in many stroke studies and has shown promising results with regard to the reduction of infarct size and improvement of functional recovery. Citicoline (CDPcholine or cytidinediphosphate choline; cytidine $5^{\prime}$-diphosphocholine) is a complex organic molecule composed of 
ribose, pyrophosphate, cytosine and choline [1]. Citicoline has been suggested to provide beneficial recovery and neuroprotective effects in brain traumatic injuries, stroke, brain ageing and neurodegenerative diseases [2,3], although the exact mechanisms through which it operates are not fully understood.

The most recent clinical and pre-clinical updates have been published by Davalos and Secades [ 4]. In this article, they provide information on basic research studies using animal models, where individual studies have demonstrated for example, increased protection against cognitive impairment in chronic hypoperfused rats [ 5], as well as a metaanalysis of the effects of citicoline using a systematic review of all the data collected (15 studies on focal ischaemia using the rat model). Here, Giralt et al. [ 6] showed overall a reduced infarct volume of 30\% (transient occlusion) and $25 \%$ (permanent occlusion), however disappointingly, there was no improvement in neurological outcome. Finally, Saver et al., [ 7] performed a meta-analysis using 10 trials of ischaemic/haemorrhagic stroke where the patients were treated with citicoline. Results showed that citicoline treatment was associated with a significant reduction in the frequency of death and disability at long-term follow up with no adverse affects. In all instances, citicoline was administered within $24 \mathrm{~h}$ of the stroke occurrence. Interestingly, 'priming' of patients with citicoline following transient ischaemic attack (TIA) or minor stroke has not been considered as yet and also, since the mechanism of its action is not fully elucidated, optimal application cannot be determined accurately.

In terms of analysis of the signalling mechanisms associated with citicoline-induced protection, Krupinski et al., [ 8] showed that citicoline treated animals showed a dramatic reduction in immunoreactive cells for pro-caspases $1,2,3,6$ and 8 in the ischemic infarction area when compared with the control group. The number of cells expressing cleaved caspase-3 and nuclear DNA fragmentation in the penumbra area was significantly reduced in animals treated with citicoline. The data suggests that citicoline may protect the ischemic neurons by providing a negative effect on the activation of the caspase apoptotic pathway.

As far as we are aware, no-one has examined the possible beneficial effects of citicoline treatment on revascularization and angiogenesis after stroke. Our preliminary in vitro studies have shown that citicoline also protects human brain microvascular endothelial cells (hCMEC/D3) against apoptosis and excitotoxic damage, strongly induces angiogenesis and significantly increases vascularisation in stroke affected regions of rats following MCAO through a signalling pathway involving activation of the insulin-receptor-substrate-1 (IRS-1), suggesting a novel protective mechanism of action and potential clinical application for improvement of tissue reperfusion and neuronal survival after ischaemic stroke.

\section{Methods}

\section{Cell culture}

Human brain micro-vessel endothelial cell (EC) line named hCMEC/D3 was grown in endothelial basal medium-2 (EBM-2) medium supplemented with growth factors and hydrocortisone as described previously [ 9]. Cells were seeded into T25 flasks pre-coated with $0.1 \%$ collagen and maintained in a humidified $5 \% \mathrm{CO}_{2}$ atmosphere at $37^{\circ} \mathrm{C}$. Every three days reaching the confluence, the cells were detached under the enzymatic activity of the trypsin then the cells in suspension were centrifuged for $5 \mathrm{~min}$ at $1300 \mathrm{rpm}$ then seeded into new pre-coated T25 flasks. Throughout the study, the cells used were between passages 28 and 38. Cells were routinely cultured as described in our previously published work [ 10].

\section{Staurosporin/ionophore-induced apoptosis assay}

In this assay, glass coverslips were sterilized in a bath of $100 \%$ ethanol for 10-20 min then left to air dry. The coverslips were put in a 24 -well plate and pre-coated with $500 \mu \mathrm{l}$ of $0.1 \%$ collagen in acetic acid and then incubated for $1 \mathrm{~h}$ hCMEC/D3 were cultured in complete medium at a concentration of $5 \times 10^{4}$ cells $/ \mathrm{ml}$ on collagen pre-coated coverslips for $4 \mathrm{~h}$-incubation. Then, the medium was replaced with serum-free medium and the cells were incubated. After $24 \mathrm{~h}$ incubation, the cells were pre-incubated with $10 \mu \mathrm{M}$ citicoline for $4 \mathrm{~h}$ prior to apoptosis induction. After the pre-incubation with citicoline, apoptosis was induced using calcium ionophore $(10 \mu \mathrm{M} / 24 \mathrm{~h})$; or staurosporin: $10 \mu \mathrm{M} / 4$ $\mathrm{h}$ (concentrations determined from pilot studies as optimal) or by exposure to oxygen-deprivation $\left(12 \mathrm{~h}, 1 \% \mathrm{O}_{2}\right.$; hypoxia confirmed by up-regulation of HIF-1 $\alpha$ as determined in our pilot studies). These concentrations have previously been shown to induce apoptosis in about 40-90\% of the cell population. For staining, one hour before the termination of the experiment, propidium iodide (PI; $10 \mu \mathrm{g} / \mathrm{ml}$ ) was added in each well as an indicator of DNA damage. After $1 \mathrm{~h}$, the medium was discarded and the cells were washed with PBS then fixed with $4 \%$ paraformaldehyde for $20 \mathrm{~min}$ at room temperature. Subsequently, cells were washed three times with PBS and exposed to $1 \mu \mathrm{g} / \mathrm{ml}$ Hoechst 6024 stain solution diluted in PBS at room temperature for $30 \mathrm{~min}$. Finally, the cells were washed three times with PBS and one drop of FluorSave ${ }^{\mathrm{TM}}$ reagent was added on frosted glass slides and the coverslips were put upside down on the drops. An average of six fields at x 200 of magnification was photographed per coverslip using an Axivoert fluorescence microscope. The apoptotic index is expressed as the number of apoptotic cells relative to the total number of cells (\% apoptotic cells). In this experiment, triplicate wells were run for each condition with controls consisting of untreated cells. 
hCMEC/D3 cells were seeded at a concentration of $8 \times 10^{4}$ cells $/ \mathrm{ml}$ in $500 \mu \mathrm{l}$ of complete basal medium in each well of 24-well plate. After $4 \mathrm{~h}$, the medium was changed to serum-poor medium (SPM) containing $1 \%$ FBS containing different concentrations of citicoline $(1 \mu \mathrm{M}, 10 \mu \mathrm{M}$ and $100 \mu \mathrm{M}$; NOTE; pilot experiments were carried out using 1$100 \mu \mathrm{M}$ citicoline and optimized for the use of $10 \mu \mathrm{M}$ subsequently as this produced the most prominent responses). After $72 \mathrm{~h}$ incubation, cells were washed with PBS and detached with trypsin. Cells were counted in a Coulter counter at least three times for each well. In this experiment, cells were treated in triplicate for each experimental condition. Cell migration (Boyden Chamber: chemotaxis assay)- Inserts of Transwell Costar ${ }^{\circledR}$ porous membranes were coated with $0.1 \%$ collagen and left for air dry in a 24 -well plate. (Wound recovery)-cells were seeded onto plastic coverslips and when confluent, were scraped with a razor to induce straight lesions. Cells were seeded in $100 \mu \mathrm{L}$ of serum- poor medium containing $1 \% \mathrm{FBS}$ at a concentration of $7.3 \times 10^{4}$ cells $/ \mathrm{ml}$. The inserts containing hCMEC/D3 were placed in a 24 -well plate containing $500 \mu \mathrm{l}$ of serum poor medium containing $1 \% \mathrm{FBS}$ and supplemented with either citicoline $(10 \mu \mathrm{M} / \mathrm{ml})$ or FGF-2 $(25 \mathrm{ng} / \mathrm{ml})$, used as a positive control. Cells were treated in triplicate for each experimental condition. (Boyden chamber)-After $24 \mathrm{~h}$ incubation, the medium was removed from the insert and the cells which had migrated through the pores to the bottom side of the insert were fixed with $4 \%$ paraformaldahyde. Cotton swabs were soaked with PBS and used in order to remove the cells that did not migrate. After fixation, the migrated cells were stained with Giemsa ( 3 minutes). An optical microscope was used to count randomly five microscopic fields from each insert. (Wound healing)-after $24 \mathrm{~h}$ the plastic coverslips were fixed in paraformaldehyde and cell migration examined under a microscope at low power. Tube-like structure formation in Matrigel- EC $\left(2 \times 10^{6}\right.$ cells $\left./ \mathrm{ml}\right)$ were mixed with

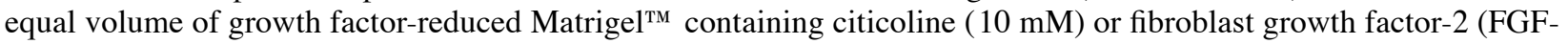
2) $(25 \mathrm{ng} / \mathrm{ml})$. Any material in the contact with the gel was cold to avoid the gel polymerization. In a 48 -well plate, a total amount of $35 \mu \mathrm{l}$ of this mixture was placed in a tear-like drop in the middle of the well and left to polymerize for $1 \mathrm{~h}$ incubation. Then, $0,5 \mathrm{ml}$ of complete medium was added into each well. After $24 \mathrm{~h}$ incubation, $4 \%$

paraformaldahyde was added to fix the endothelial tube-like structures embedded in the gel. Five areas from each well were counted under optical microscope. Spheroids were produced by inoculation of centrifuged endothelial cells into matrigel with or without addition of citicoline or FGF-2 as a positive control and their development including sprout formation monitored as described above over a period of 7 days. At least 10 sprouts were measured for each condition and the experiments repeated at least 3 times.

\section{Protein extraction and western blotting}

EC $\left(3 \times 10^{5}\right.$ cells $\left./ \mathrm{ml} ; 2 \mathrm{ml}\right)$ were seeded in complete medium in 6-well plate and incubated for $48 \mathrm{~h}$. Then, the medium was replaced with SPM containing $1 \%$ FBS. After $24 \mathrm{~h}$ incubation, the cells were stimulated with citicoline at 1-10-50 $\mu \mathrm{M}$ for $10 \mathrm{~min}$ then the cells were immediately washed with $1 \mathrm{ml}$ of PBS and gently lysed on ice in $50 \mu \mathrm{l}$ of ice-cold homogenized lysis buffer (PH 7.2). The cells then were scraped, the cell lysate proteins collected and transferred into $0.5 \mathrm{ml}$ micro-centrifuge tubes. Samples were sonicated four times for 10 seconds each time with 10-15 second intervals on ice to rapture the cells and to shear nuclear DNA. Cell lysates were centrifuged at 20,000 g for $20 \mathrm{~min}$ and the protein concentration was determined using the BioRad protein assay.

In our preliminary un-published studies, we showed that citicoline also strongly induced angiogenesis in our bovine aortic EC (BAEC) and for this reason we performed a phospho-site protein expression screen using Kinex ${ }^{\mathrm{TM}}$ antibodies microarray KAM1.3 and performed by Kinexus (Bioinformatics Corporation, Vancouver, Canada). The most relevant phospho-protein expression up- or down-regulated by citicoline were confirmed by Western blotting (IRS-1, HER2 and Histone H2B; see additionally supplied data). Since phosphorylation of IRS-1 was most apparent when translated to our hCMEC/D3 cells, we investigated its role in intracellular signalling in more detail here. Standard siRNA transfection (using lipofectamine) was employed to induce a transient down-regulation of IRS-1 RNA (approximately 85-90\%-data not included; Figure 1B and C). After $24 \mathrm{~h}$ exposure to siRNA or scrambled sequences, cells were used for analysis of tube-like structure formation described previously. The experiment was repeated twice in triplicate wells and a representative example shown.

\section{Figure 1}




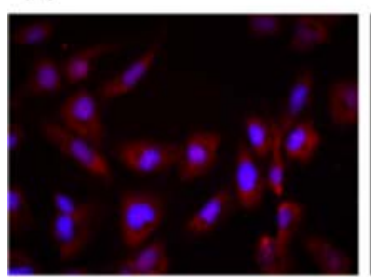

i

B

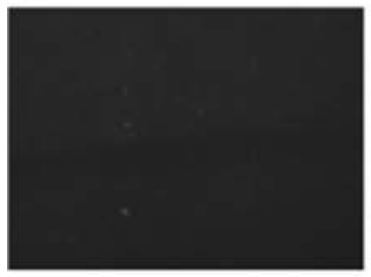

i

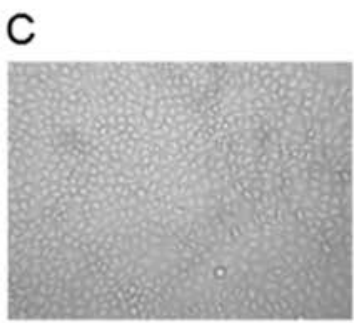

i

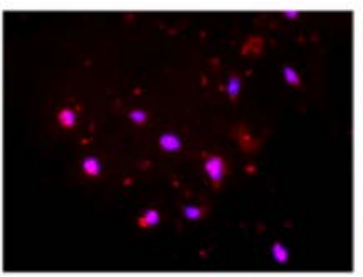

ii

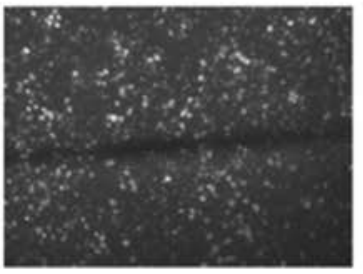

ii

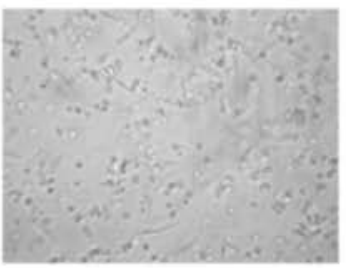

ii

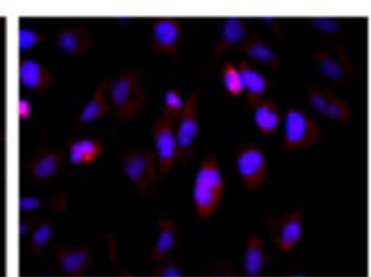

iii

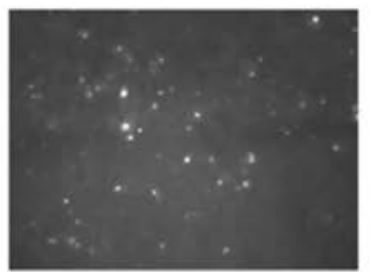

iii

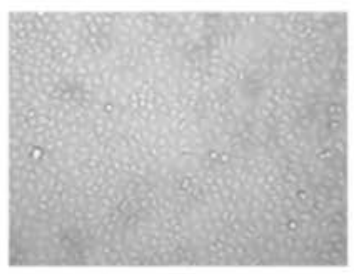

iii
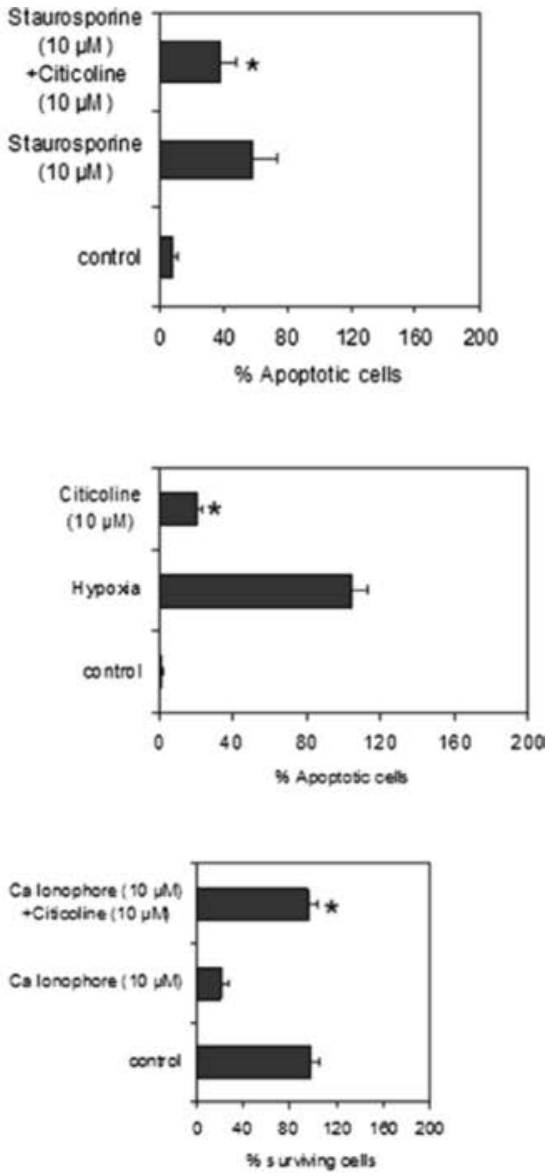

Effect of citicoline, hypoxia, and the Ca ionophore A23187 on cell death in hCMEC/D3. A) Shows control hCMEC/D3 without citicoline or staurosporin treatment (i), cells treated with staurosporin (ii; $10 \mu \mathrm{M}$ ), and cells pre-incubated with citicoline for $4 \mathrm{~h}$ before apoptosis was induced with $10 \mu \mathrm{M}$ staurosporin $(24 \mathrm{~h}$; iii). The presence of citicoline $(10 \mu \mathrm{M})$ was sufficient to significantly inhibit cell apoptosis (iii) B) Shows control hCMEC/D3 without citicoline or hypoxia treatment (i), cells treated after exposure to hypoxia (ii; $12 \mathrm{~h} ; 1 \% \mathrm{O}_{2}$ ) and cells pre-incubated with citicoline for $4 \mathrm{~h}$ prior to subjecting to hypoxia (iii). The data shows that citicoline (10 $\mu \mathrm{M}$ ) was able to significantly reduce the number of cells undergoing apoptosis (iii). C) Shows that citicoline protected the cells against apoptosis induced by calcium ionophore. (i) Shows control cells, (ii) the effect of 10 $\mu \mathrm{M} / 24 \mathrm{~h}$ treatment with $\mathrm{Ca}$ ionophore, and (iii), the effect of $4 \mathrm{~h}$ pre-treatment with citicoline before addition of 10 $\mu \mathrm{M}$ Ca ionophore. Citicoline significantly protected against apoptosis induced by the ionophore. The bar graphs shows data from one representative experiment carried out in triplicate wells. All experiments were performed three times. Cells were considered apoptotic when cell nuclei demonstrated positive PI/Hoechst staining and apoptotic morphology (Data not shown). For quantification of PI/Hoechst -positive cells, four fields per section were examined at 200-fold magnification. The apoptotic index was calculated using the formula: Apoptotic index $=$ $100 *$ (number of PI/Hoescht + cell nuclei per field/total number of cell nuclei per field).

\section{Transient rat MCAO}

Four male Wistar rats (Charles River) were used in each group (control and citicoline treated), with a weight of 280$320 \mathrm{~g}$ at the beginning of the study. Animals were kept on a 12/12 hours light/darkness cycle, with access to food and water ad libitum .

The ischemic lesion was induced by transient (90 minutes) occlusion of the right middle cerebral artery (MCAO), using the intraluminal thread occlusion method, described elsewhere [11], under isofluorane anesthesia. The occlusion period and the successful reperfusion of the right MCA were controlled by continuous recordings of ipsilateral laserDoppler flowmetry (LDF). Animals were intraperitoneally treated with either citicoline ( $1000 \mathrm{mg} / \mathrm{Kg})$ or saline. Drugs were daily administered until day 7. The first dose was given 15 minutes before reperfusion. 21 days after occlusion animals were anesthetized and perfused through the heart with heparinized saline, followed by $4 \%$ paraformaldehyde. Brains were cryoprotected with $30 \%$ sucrose, frozen at $-40^{\circ} \mathrm{C}$ and $8-\mu \mathrm{m}$ thick coronal sections were cut in a cryostat. 1, 7 and 21 days after occlusion rats were anesthetized and MRI T2-weighted images were acquired at 7 T (Bruker BioSpin), in order to study evolution of lesion volume. There was no mortality in this experimental group. Procedures followed were in accordance with institutional guidelines.

\section{Immunohistochemistry}

Immunohistochemical staining was used to determine the relative numbers of microvessels (anti-CD31) and active vessels (anti-CD105) in control and citicoline treated stroked brain tissue after 21 days $(n=5)$. The mean number of vessels from five areas of stroke-affected tissue was counted microscopically $(\times 20)$ in eight sections per animal. 
Double immunofluorescence was used to assess the distribution of the phospho-protein IRS-1 in relation to active microvessels in the stroke region (CD105/endoglin mouse monoclonal antibody). After incubation with primary antibodies for $1 \mathrm{~h}$ at room temperature (1:100), sections were washed and then incubated with the appropriate secondary antibodies (1:50) - fluorescein isothiocyanate-conjugated sheep anti-mouse IgG (Jackson) or tetramethylrhodamineisothiocyanate-conjugated rabbit anti-goat (Jackson). Images were captured with Nikon 80i Digital Microscope using Nis Elements 3.21 software with multichannel capture option. Negative control slides were included where the primary antibody was replaced with PBS.

\section{Statistical analysis}

All in vitro experiments were performed at least three times and the results are expressed as the means \pm S.D. Section analysis by immunohistochemistry involved counting the numbers of microvessels from 5 regions within the infarcted tissue and from 3 separate sections (1, 5, and 10 from serial sections) for each condition. Statistical significance was tested by Student's $t$-test and data were considered significant when $\mathrm{p} \leq 0.05$.

\section{Results}

\section{Citicoline protects hCMEC/D3 against cell damage/apoptosis}

EC were pre-incubated with $10 \mu \mathrm{M}$ citicoline for $4 \mathrm{~h}$. Then, the cells were incubated with 1-10 $\mu \mathrm{M}$ staurosporin in DMSO for $4 \mathrm{~h}$ and $24 \mathrm{~h}$, respectively. These concentrations were chosen in order to identify appropriate levels of cell damage/apoptosis and were classified as preliminary studies. In these experiments, the numbers of apoptotic cells were approximately $40 \%$ and $60 \%$ at $10 \mu \mathrm{M}$ ( $4 \mathrm{~h}$ and $24 \mathrm{~h}$ respectively) (data not shown). Therefore, $10 \mu \mathrm{M} / 4 \mathrm{~h}$ was the chosen treatment in order to evaluate whether citicoline could protect the cells against cell death pathways. Pretreatment of hCMEC/D3 cells with citicoline significantly decreased the number of damaged/apoptotic cells, determined by counting the numbers of PI-positive nuclei at the end of the experiment, under these conditions (Figure $1 \mathrm{~A} ; \mathrm{P}<0.05)$. Since hypoxia is a key feature of acute ischaemic stroke and a major activator of cell apoptotic pathways, we examined its effect on our EC in the presence of citicoline (10 $\mu \mathrm{M} / 4 \mathrm{~h}$ pre-incubation). Again, the presence of citicoline in the media significantly protected the cells against apoptosis/cell damage (Figure $1 \mathrm{~B} ; \mathrm{p}<$ $0.05)$. Increased expression of and release of $\mathrm{Ca}^{2+}$ Kainic acid and glutamate also leads to increased cell death after stroke. Ionophore treatment of EC is known to induce Ca influx and rapid dephosphorylation of eNOS at Thr495 resulting in eNOS activation. For this reason, we exposed our EC to the Ca ionophore A23187 (10 $\mu \mathrm{M} / 24 \mathrm{~h})$, after pretreatment with citicoline. Figure $1 \mathrm{C}$ shows that the $\mathrm{Ca}$ ionophore caused significant reduction in survival of cells after $24 \mathrm{~h}$. However in the presence of citicoline, the effects were reversed and the cells remained attached and morphologically identical to control-untreated cells $(\mathrm{p}<0.05)$. The possible mechanism through which citicoline provides this protection is discussed later in this results section.

\section{Discussion}

In this study, we have, for the first time, demonstrated both a vascular protective, and pro-angiogenic effect of citicoline using in vivo and in vitro models. Here we show the strong protective effect of citicoline on brain microvascular EC, demonstrated by the ability of citicoline to protect against either calcium ionophore or hypoxiainduced cell damage/apoptosis identified by nuclear uptake of propidium iodide. Previous studies have shown that citicoline was able to protect motor neurons of organotypic rat lumbar spinal cord cultures, from apoptosis following administration of the excitotoxic agent DL-threo- $\beta$-hydroxyaspartate (a glutamate analogue) [ 13]. Similarly, citicoline with or without hypothermia, protected neurons against apoptosis in a rat model of transient focal MCAO through a mechanism including the modulation of Bcl-2, Bax and caspase-9 [ 14]. In other cell types/sources, citicoline protected against cell damage from Kainic acid in retinal neurons [15] and indirectly, may protect lung adenocarcinoma cells (A549) against apoptosis [ 16,17]. No studies until now have been carried out using EC. Our data suggests a strong protective effect against the damaging process of excitotoxicity and hypoxia, similar to that experienced after acute ischaemic stroke. In regard to the possible mechanism? Our kinexus phospho-protein screen identified a tenfold reduction in expression of Histone H2B (serine 14). Phosphorylation of histone H2B at serine 14 (S14), a posttranslational modification required for nuclear condensation, correlates with cells undergoing programmed cell death in vertebrates [ 18]. The authors of this paper also identified a $34 \mathrm{kDa}$ apoptosis-induced H2B kinase as caspase-cleaved Mst1 (mammalian sterile twenty) kinase. Mst1 can phosphorylate $\mathrm{H} 2 \mathrm{~B}$ at S14 in vitro and in vivo, and the onset of H2B S14 phosphorylation is dependent upon cleavage of Mst1 by caspase-3. These data reveal a histone modification that is uniquely associated with apoptotic chromatin and provide insights into a previously unrecognized physiological substrate for Mst1 kinase. Further experiments are needed to confirm that these findings represent a key novel mechanistic pathway for EC protection associated with citicoline treatment.

In addition, although citicoline had no effect on the chemotaxis of HBMEC/D3 determined by using the Boyden chamber method it significantly increased the number of migrating cells in the scratch wound healing assay. Citicoline also significantly increased the formation of tube-like structure in Matrigel producing a stronger effect than the known mitogenic factor FGF-2 ( $\mathrm{p}<0.05$ ). Although citicoline had no mitogenic and chemotactic effects on EC, it had a significant effect on cell differentiation and migration which are two of the key steps of the angiogenic process. This may be an extremely valuable novel finding in regard to understanding the potential mechanisms through which 
citicoline treatment results in patient recovery, since both protection of EC and induction and maintenance of angiogenesis is key to both short-term and chronic re-vascularization after stroke impacting indirectly but significantly also on neuronal survival and re-integration [19].

Western blotting demonstrated that citicoline induced pERK1/2 expression, a key mitogenic signalling protein known to be involved in angiogenesis and generally stimulated by growth factors through interaction with their receptors [ 20]. This data demonstrated the potential of citicoline to activate intra-cellular signal transduction pathways and induce phosphorylation of down-stream angiogenic molecules; hence we investigated this ability in more detail by analysis of the Kinexus-phospho-protein Western screen following treatment of vascular EC with citicoline. Interestingly, treatment with citicoline modified the expression of only several of the $>500$ proteins on the array showing a degree of specificity. IRS-1 and Her2 were both phosphorylated in the presence of citicoline. These two proteins have not been implicated in stroke recovery pathways or stroke angiogenesis until now.

Here, we went on to demonstrate the importance of IRS-1 in mediating the angiogenic effects of citicoline in vitro , and further showed localization of p-IRS-1 in the vascular regions of peri-infarcted tissue of animals 21 days after MCAO but only following treatment with citicoline. The vessels were nearly always thin-walled neo-vessels with minimal or no pericyte coverage and CD105-positive suggesting dynamic activity and contribution to the revascularisation process.

Only recently, IRS-1 over-expression was attributed to increased angiogenesis in human EC in association with increased Akt and VEGF-A expression [ 12], whilst in vivo , antisense IRS-1 sequences delivered by sub-conjunctival injection inhibited rat corneal neovascularisation [21], and when delivered by means of eye-drops (GS-101) were found to be tolerable in a phase- 1 clinical trial and may be sufficient to prevent neovascularisation in disease such as retinopathy and neovascular glaucoma [ 22]. Therefore, IRS-1 represents a potent modulator of pro-angiogenic signalling cascades in vascular EC and as such, since we have shown both in vitro , and in the rat model of temporary MCAO that citicoline induces phosphorylation of IRS-1 and concomitant EC activation and increased vascularisation, this could be a key novel mechanism of action of citicoline.

A further interesting finding was the up-regulation of HER2 by citicoline in our vascular ECs in vitro. Although we have not investigated this in more detail within this piece of work or in our hCMEC, HER2 has previously been shown to be important in promotion of angiogenesis and concomitant tumour breast tumour growth [ 23], and is strongly implicated in activation of intracellular signalling pathways increasing the expression of VEGF and IL-8 [ 24]. Therefore, further investigation is warranted to determine its importance in the induction of citicoline-associated angiogenesis and vascularisation after ischaemic stroke.

\section{Conclusion}

In conclusion, citicoline induces angiogenesis and improves survival of human brain microvessel endothelial cells through pathways involving p-ERK1/2, and IRS-1 and it is probable that other novel signalling intermediates are also involved including Histone H2B and HER2 (more studies are needed to confirm this) and therefore following chronic treatment, its beneficial effects after stroke may in part be due to revascularization. Based on our findings, optimization of its therapeutic use to include vascular tissue regeneration should be re-considered.

\section{Disclosures}

Authors have no additional disclosures.

\section{Sources of funding}

This study was supported from research grant from Ferrer International.

Additional file 1: Figure S1. Kinexus bar chart. (TIFF 86 KB)

\section{Declarations}

\section{Authors' original submitted files for images}

Below are the links to the authors' original submitted files for images.

Authors' original file for figure 1

Authors' original file for figure 2

Authors' original file for figure 3 
Authors' original file for figure 4

Authors' original file for figure 5

Authors' original file for figure 6

\section{Competing interests}

The authors declare that they have no competing interests.

\section{Authors' contributions}

JK, MS and JS designed the experimental protocols/project management and drafted the manuscript; MA, SM and DL performed the experimental work in vitro; CA and JP performed the in vivo studies; RA, NR, MG and EP helped to design the study and prepare the manuscript. All authors read and approved the final manuscript.

\section{References}

1. Secades JJ. Probably role of citicoline in stroke rehabilitation: review of the literature. Rev Neurol. 2012;54:173-179.

View Article Google Scholar

2. Blount PJ, Nguyen CD, McDeavitt JT. Clinical use of cholinomimetic agents: a review. J Head Trauma Rehabil. 2002;17:314-321.

View Article Google Scholar

3. Hurtado O, Cárdenas A, Pradillo JM, Morales JR, Ortego F, Sobrino T, et al. A chronic treatmente with CDPcholine improves functional recovery and increases neuronal plasticity after experimental stroke. Neurobiol Dis. 2007;26:105-111.

View Article Google Scholar

4. Davalos A, Secades J. Citicoline preclinical and clinical update 2009-2010. Stroke. 2011;42:S36-S39. View Article Google Scholar

5. Lee HJ Kang JS Kim YI Citicoline protects against cognitive impairment in a rat model of chronic cerebral hypoperfusion J Clin Neurol 2009533382686890 10.3988/jen.2009.5.1.33

6. Giralt D, Garcia-Bonilla L, Campos M, Sosti V, Rosell A, Montaner J. Selecting the optimal dose of citicoline treatment in animal models of focal cerebral ischaemia through a meta-analysis. Cerebrovasc Dis. 2010;29:165-.

View Article Google Scholar

7. Saver JL. Citicoline: updata on a promising and widely available agent for neuroprotection and neurorepair. Rev Neurol Dis. 2008;5:167-177.

View Article Google Scholar

8. Krupinski J, Ferrer I, Barrachina M, Secades JJ, Mercadal J, Lozano R. CDP-choline reduces pro-caspase and cleaved caspase- 3 expression, nuclear DNA fragmentation, and specific PARP-cleaved products of caspase activation following middle cerebral artery occlusion in the rat. Neuropharmacology. 2002;42:846-854.

View Article Google Scholar

9. Weksler BB, Subileau EA, Perriere N, Charneau P, Holloway K, Leveque M, et al. Blood-brain barrierspecific properties of a human adult brain endothelial cell line. FASEB J. 2005;19:1872-1874.

View Article Google Scholar

10. Slevin M, Matou-Nasri S, Turu M, Luque A, Rovira N, Badimon L, et al. Modified C-reactive protein is expressed by stroke neovessels and is a potent activator of angiogenesis in vitro. Brain Pathol. 2010;20:151-165.

View Article Google Scholar

11. Longa EZ, Weinstein PR, Carlson S, Cummins R. Reversible middle cerebral artery occlusion without craniectomy in rats. Stroke. 1989;20:84-91. 
12. Al-Mahmood S, Colin S, Farhat N, Thorin E, Steverlynck C, Chemtob S. Potent in vivo antiangiogenic effects of GS-101 (5'-TATCCGGAGGGCTCGCCATGCTGCT-3') an antisense oligonucleotide preventing the expression of insulin receptor substrate-1. J Pharmacol Exp Ther. 2009;329:496-504. View Article Google Scholar

13. Matyja E, Taraszewska A, Naganska E, Grieb P, Rafalowska J. CDP-choline protects motor neurons against apoptotic changes in a model of chronic glutamate excitotoxicity in vitro. Folia Neuropathol. 2008;46:139-148.

View Article Google Scholar

14. Sahin S, Alkran T, Temel SG, Tureyen K, Tolunay S, Korfali E. Effects of citicoline used alone and in combination with mild hypothermia on apoptosis induced by focal cerebral ischaemia in rats. J Clin Neurosci. 2010;17:227-231.

View Article Google Scholar

15. Han YS, Chung IY, Park JM, Yu JM. Neuroprotective effect of citicoline on retinal cell damage induced by kainic acid in rats. Korean J Ophthalmol. 2005;19:219-226.

View Article Google Scholar

16. Joo JH Jetten AM Molecular mechanisms involved in farnesol-induced apoptosis Cancer Lett 2010 287123 1352815016 10.1016/j.canlet.2009.05.015

17. Miquel K, Pradines A, Terce F, Selmi S, Favre G. Competetive inhibition of choline phosphotransferase by geranylgeraniol and farnesol inhibits phosphatidylcholine synthesis and induces apoptosis in human lung adenocarcinoma A549 cells. J Biol Chem. 1998;273:26179-26186.

View Article Google Scholar

18. Cheung WL, Ajiro K, Samejima K, Kloc M, Cheung P, Mizzen CA, et al. Apoptotic phosphorylation of histone H2B by mammalian sterile twenty kinase. Cell. 2003;113:507-517.

View Article Google Scholar

19. Mitsios N, Gaffney J, Kumar P, Krupinski J, Kumar S, Slevin M. Pathophysiology of acute ischaemic stroke: an analysis of common signalling mechanisms and identification of new molecular targets. Pathobiol. 2006;73:159-175.

View Article Google Scholar

20. Slevin M, Kumar P, Gaffney J, Kumar S, Krupinski J. Can angiogenesis be exploited to improve stroke outcome? Mechanisms and therapeutic potential. Clin Sci. 2006;111:171-183.

View Article Google Scholar

21. Andrieu-Soler C, Berdugo M, Doat M, Courtois Y, BenEzra D, Behar-Cohen E. Down-regulation of IRS-1 expression causes inhibition of corneal angiogenesis. Invest Ophthalmol Vis Sci. 2005;46:4072-4078.

View Article $\underline{\text { Google Scholar }}$

22. Kain H Goldblum D Geudelin B Thorin E Beglinger C Tolerability and safety of GS-101 eye drops, an antisense oligonucleotide to insulin receptor substrate-1: a first in man phase 1 investigation Br J Clin Pharmacol 2009681691732767278 10.1111/j.1365-2125.2009.03450.x

23. Foy KC Liu Z Phillips G Miller M Kaumaya PT Combination treatment with HER-2 and VEGF peptide mimics induces potent anti-tumour and anti-angiogenic responses in vitro and in vivo $\mathrm{J}$ Biol Chem 201128613626136373075707 10.1074/jbc.M110.216820

24. Wen XF, Yang G, Mao W, Thornton A, Liu J, Bast RC, Le XF. HER2 signaling modulates the equilibrium between pro-and antiangiogenic factors via distinct pathways: implications for HER2 -targeted antibody therapy. Oncogene. 2006;25:6986-6996.

View Article Google Scholar 